\title{
¡NO ES UN ALGO, PERO TAMPOCO ES UNA NADA! MENTE Y NORMATIVIDAD ${ }^{1}$
}

\author{
Manuel de Pinedo
}

\begin{abstract}
RESUMEN
Partiendo de un marco que evita tanto el descriptivismo como el eliminativismo con respecto a nuestro vocabulario mental y a nuestras prácticas normativas, en este trabajo se exploran los argumentos de Strawson y Sellars a favor de la prioridad de los conceptos de persona, razón y objeto frente a los de mente, ley y sensación.
\end{abstract}

PALABRAS CLAVE: Descriptivismo, eliminativismo, normatividad, Strawson, Sellars.

\section{ABSTRACT}

This essay situates within a non-descriptivist and non-eliminativist framework regarding our mental vocabulary and normative practices the classic arguments, due to Strawson and Sellars, for the priority of the concepts of person, reason and object over those of mind, law and sensation.

KEYWORDS: Descriptivism, eliminativism, normativity, Strawson, Sellars.

\section{INTRODUCCIÓN}

La herencia cartesiana en el pensamiento sobre la mente parece inagotable. El rechazo que su dualismo recibió desde el principio dejó intacto

\footnotetext{
${ }^{1}$ Este artículo debe mucho a discusiones con Hilan Bensusan, María José Frápolli, Manuel Heras y Neftalí Villanueva. Una versión anterior de algunas partes del mismo apareció publicada en la revista Daimon (Pinedo 2002).
} 
el compromiso con el acceso incorregible que ésta tiene a sus contenidos. Tampoco fueron suficientes las críticas a la introspección como forma de conocimiento. La siguiente característica del cartesianismo que levantó sospechas fue el representacionalismo. La mente, en las concepciones dominantes en filosofía y psicología (funcionalismo y cognitivismo), es una entidad objeto de estudio científico cuya principal función es computar sobre representaciones del mundo. Es tentador pensar que una refutación del representacionalismo supondría el golpe de gracia para Descartes. Sin embargo, por debajo de dualismo, incorregibilidad y representacionalismo había un compromiso ontológico muy fuerte con la idea de que la mente era una sustancia, un órgano. Negar que el órgano no esté hecho de materia física ordinaria, que lo caracteriza su intimidad consigo mismo o que construye representaciones del mundo es todavía insuficiente. Tras una gran parte del antirrepresentacionalismo contemporáneo subyace otra forma de representacionalismo, esta vez no con respecto a la mente, sino con respecto al lenguaje. Se trata de la idea de que la única función del lenguaje aseverativo es referir a objetos y describirlos.

Esta idea, criticada como "falacia descriptiva" por Austin (1962, p. 3) fue también rechazada por Wittgenstein (1953) o Ryle (1949), en ambos casos con especial atención a lo mental. Sin embargo, hasta los últimos veinte años, ha seguido siendo inusual considerar que la principal lección sobre la mente que podemos aprender de estos filósofos sea su oposición al descriptivismo o a su correlato ontológico, el factualismo. Más recientemente, se ha ido perfilando una perspectiva positiva que se opone al descriptivismo: el expresivismo. Inicialmente presentada como teoría del significado de nuestras proferencias éticas (p.e., Gibbard, 1990), se han ido proponiendo variantes para diversos ámbitos normativos: lógica (Brandom, 2000; Frápolli, 2012), epistemología (Chrisman, 2007) o autoconocimiento (Finkelstein, 2008). Este creciente consenso heterodoxo ha recibido un impulso importante por parte de algunos de los filósofos que participan en este volumen. Huw Price (2011) ha articulado una posición antirrepresentacionalista general a partir de las ideas de Wittgenstein y de propuestas expresivista. María José Frápolli (junto a Neftalí Villanueva) ha presentado una propuesta de expresivismo global mínimo (2012).

El presente trabajo se enmarca dentro de dicho proyecto expresivista y antidescriptivista y explora algunos antecedentes poco discutidos en este contexto. En la primera parte ("I. Personas y razones") haré uso de los 
argumentos de Strawson en favor del papel central del concepto de "persona". Si nuestra concepción de la mente y de la conciencia son derivadas de nuestra concepción de las personas, y las personas son entidades a las que puede adscribirse tanto características mentales como físicas, la urgencia de mostrar cómo se relacionan mente y mundo empieza a desaparecer. En la segunda parte ("II. Objetos y sensaciones") revisaré la crítica de Sellars al mito de lo dado para defender la irreductibilidad de los objetos observables a colecciones de sensaciones y para apoyar lo que Strawson ha llamado la 'actitud natural'. Me separaré, no obstante, de la concepción que Sellars tiene de dicha actitud, a la que él llama 'imagen manifiesta', como una teoría apta para ser sustituida por otra, la representada por la 'imagen científica', y defenderé que la actitud natural no es un conjunto de ideas que tenemos, sino que son "creencias en las que estamos”, por usar la expresión de Ortega y Gasset (1940, pp. 17ss.). Mantendré que el papel de la ciencia sólo puede comprenderse dentro de la esfera más amplia de la racionalidad humana. Aún siendo cierto que los cánones internos ofrecidos por las teorías científicas para evaluar sus resultados y para compararlos con los resultados de otros paradigmas científicos y, especialmente, con los de otras supuestas formas de obtener conocimiento sobre el mundo (misticismo, religión, pero también historia y las demás humanidades) no son suficientes para mostrar la superioridad de la ciencia, de ello no se sigue que todo quepa: la cultura humana, entendida como un todo, tiene cánones de racionalidad, adecuación, utilidad práctica, etc., que pueden explicar la superioridad de la ciencia sobre, digamos, el vudú. Por supuesto, adoptar esta línea conlleva que la ciencia no está libre de valores prácticos, y que no es el juez último y único de lo que tiene sentido decir sobre el mundo. Pero sus poderes predictivos, su simplicidad y universalidad dicen mucho a su favor. Sin embargo, su aplicación a los humanos tiene una limitación fundamental: es circular esperar que la ciencia agote todo lo que sobre nosotros hay que decir, incluyendo la explicación de la tarea misma de hacer ciencia. De esta forma, la actitud natural ('la psicología popular' o 'el enfoque intencional') no puede desaparecer en su aplicación a los humanos ya que es, se defenderá, la forma humana ineludible de comprensión.

El ser humano empieza aplicando el 'enfoque intencional', en expresión de Dennett (1971), a toda la naturaleza. El clima, los planetas y estrellas, el mar, todos actúan intencionalmente. Este es el elemento más característico del pensamiento mítico: todo aquello que no puede explicarse con simplicidad tiene un dios detrás actuando caprichosa o, al menos, 
misteriosamente. Sin embargo, la humanidad ha aprendido a eliminar las explicaciones intencionales en su comprensión de la mayoría del universo. Y, sin embargo, una parte de ese universo parece escaparse continuamente a tal eliminación: la humanidad misma.

Podemos dejar de caer en la tentación de proyectar la estrategia intencional para dar sentido del comportamiento de las cosas que no parecen utilizarla (estrellas, tormentas, enfermedades). Pero no podemos dejar de usarla para comprender a las criaturas que obviamente la utilizan, los humanos, incluyéndonos a nosotros mismos. Cuando adquirimos un lenguaje, y con él un enfoque psicológico de sentido común, también adquirimos la tendencia a teorizar acerca de nuestra propia experiencia. El eliminativismo con respecto a la psicología intencional corre el peligro de cortar su propio fundamento: el programa de esa eliminación es él mismo un programa intencional.

Sin embargo, es fácil ver lo tentador que ese programa es. Después de todo, hemos sido capaces de eliminar cualquier mención a la racionalidad en nuestra comprensión del resto de la naturaleza. ¿Por qué tenemos que ser diferentes? En este trabajo defenderé lo somos debido precisamente a nuestra capacidad de intentar comprender nuestro lugar en el universo y que tales intentos no pueden entenderse desde fuera de sí mismos. Una aproximación descriptiva o histórica a ellos puede ser iluminadora, pero no es todo lo que puede decirse. Cualquier intento de reducir la racionalidad a un elemento extrarracional será una caída en el mito de lo dado, como lo llama Sellars, que es una forma de la falacia naturalista: no podemos derivar normas de "meros hechos", razones de "meras causas". La segunda parte de este trabajo se ocupa de la tentación de aislar un espacio puramente fáctico para a continuación reducir el ámbito de lo normativo a ese espacio, y de la supuesta dicotomía entre razón y naturaleza. No obstante, quisiera hacer algunos breves apuntes a continuación sobre la falacia naturalista y el proyecto de explicar la razón a la luz de la causalidad.

La tarea de la ciencia no es recopilar hechos, porque los hechos no están dados al margen de un marco teórico de referencia. Los hechos son hechos dentro de una teoría, y las teorías están infradeterminadas por la observación, ya que incluso lo que cuenta como observación depende de teoría e interés. La evaluación de los hechos (su pertinencia, su relación con otros hechos, su lugar en las teorías, etc.) no puede hacerse independientemente de las teorías para las que son hechos. Cualquier recurso a hechos científicos debe tomar en consideración los valores epistémicos (tales como la verdad, 
simplicidad, coherencia, etc.) que entran en juego al juzgar las teorías. Tales valores son una precondición para la labor científica y por ello no pueden reducirse ni explicarse desde ella. Son muchas las áreas del conocimiento humano que no parecen reductibles a la ciencia. El conocimiento es más amplio que la ciencia natural y quizá, como numerosos críticos continentales del positivismo han insistido a lo largo de los años, el conocimiento no científico es más importante y fundamental para los seres humanos. ${ }^{2}$ Sólo sobre la base de nuestra comprensión no científica, no nomológica, podemos dar sentido al papel de la ciencia.

\section{Personas y RAZONES}

\subsection{RACIONALIDAD: DESCRIPTIVISMO Y NORMATIVISMO}

El enfoque que sobre la racionalidad defenderé tiene su origen en la obra de Kant. Ahora bien, frente a una lectura individualista de su filosofía en la que cada persona es responsable última de la revisión (o revisabilidad) de todo su conocimiento, defenderé una lectura intersubjetiva. Esta lectura, desarrollada recientemente por Strawson y McDowell entre otros, sugiere que ninguna persona individual encarna el ideal de racionalidad; tal ideal pertenece a la cultura como un todo y cada persona se convierte en receptáculo de cultura adquiriéndola por medio del aprendizaje lingüístico.

Muchos filósofos han mantenido que negar que los animales no lingüísticos piensan es negar lo obvio. Aquí tenemos, por ejemplo, a Hume, no muy dado a tomar verdades como evidentes: "Próximo al ridículo de negar una verdad evidente está el de tomarse mucho esfuerzo por defenderla; y ninguna

\footnotetext{
${ }^{2}$ Esta es la principal tesis del Tractatus de Wittgenstein, la que sobrevive después de tirar la escalera: "Nosotros sentimos que incluso si todas las posibles cuestiones científicas pudieran responderse, el problema de nuestra vida no habría sido más penetrado" (6.52; trad.: E. Tierno Galván). Sólo la segunda parte del Tractatus, la "no escrita", es importante (como señaló en su famosa carta al editor alemán de su libro, ver Hacker, 1986, p. 105): "Desde luego que no queda ya ninguna pregunta, y precisamente ésta es la respuesta" (6.52). Esta idea, que considera a la ciencia clara pero poco iluminadora, puede también encontrarse en William James: "Ya que básicamente no somos escépticos, podríamos confesarnos los motivos para nuestras distintas fes. Yo confieso los míos con franqueza-no puedo evitar pensar que en el fondo son de naturaleza estética y no lógica" (James, 1912, p. 276; citado en Ayer, 1982, p. 72).
} 
verdad me parece tan evidente como la de que las bestias poseen pensamiento y razón, igual que los hombres" (1739-40, p. 176; trad.: F. Duque). Sería de esperar, sin embargo, que la mayoría de estos filósofos también estuviera de acuerdo en que afirmar que no existen diferencias sustanciales entre el pensar de las criaturas no lingüísticas y el de las criaturas lingüísticas es un error del mismo grado. Una cuidadosa caracterización del pensamiento y la racionalidad es precisa si queremos hacer justicia a estos dos hechos: es importante aislar aquello que hace especiales a los humanos sin traicionar las patentes similitudes que existen entre éstos y el resto del reino animal. No bastará, por ejemplo, con decir que el conocimiento humano está sujeto a revisabilidad, ya que podemos ver cómo los animales cambian sus patrones de comportamiento en el curso de su existencia. Por otra parte, sería excesivo exigir como seña de identidad la revisabilidad total, pues podemos ver con frecuencia a los humanos abrazando creencias tercamente.

Se ha señalado a menudo que, entre los animales, los humanos son los únicos que no están condenados a repetir la historia conductual de su especie a lo largo de su vida: aprendemos de nuestros cuidadores muchas de las cosas que ellos mismos han aprendido. Pero ni siquiera esto es exclusivamente humano. Es cierto que, por ejemplo, los pájaros que usan instrumentos no necesitan ver a sus mayores usándolos para aprender como hacerlo. No menos cierto es que los primates no humanos son capaces de imitar las ideas de los de su misma especie, mientras que a primates de otra comunidad puede nunca ocurrírseles (no todos son capaces de dar gritos de alarma engañosos para beneficiarse en exclusiva de un banquete, pero pueden aprender a hacerlos).

Ahora bien, la principal, si no la única, forma de transmitir información de generación en generación entre criaturas no humanas es genética. Esta información es a menudo realmente sofisticada. El "descubrimiento" de los números primos puede verse en cigarras: hay algunas especies que se reproducen cada trece o diecisiete años y así evitan que sus depredadores regulen sus ciclos reproductivos para que las crías se den un festín (ver Stephen Jay Gould 1977). Los humanos, por otra parte, tienen la habilidad especial de transmitirse información y de evitar los errores de sus progenitores. Un jugador de ajedrez principiante no necesita perder su reina una y otra vez como consecuencia de ponerla en juego demasiado pronto. Normalmente es suficiente con que se le diga. Los estudiantes de física no tienen que luchar media vida con problemas copernicanos antes de captar los principios de la 
física moderna. $\mathrm{Y}$, a pesar de las apariencias, los fumadores no necesitan perder las piernas para saber que el tabaco es perjudicial.

Las diferencias que he comentado en los párrafos previos son de carácter descriptivo, y por ello podría mantenerse que meramente cuantitativas. No son este tipo de diferencias las que quiero utilizar para caracterizar la noción de racionalidad que, defenderé, juega un papel central e ineliminable en la actitud natural. Al hablar de racionalidad no me estoy refiriendo sólo a la capacidad de aplicar reglas generales a diversos dominios y de revisar esas reglas a la luz de la experiencia y otras reglas. Me refiero más generalmente a la habilidad humana de "racionalizar", de explicar, comprender y justificar el comportamiento de uno y de los demás. Entendida de esta forma, la racionalización no es una práctica que describe y predice lo que alguien hace o hará, cree o creerá, sino que su tarea primordial es desentrañar lo que alguien debería hacer o creer a la luz de lo que de hecho hace y cree. Y, por supuesto, a luz también de nuestra incapacidad de interpretar la conducta de las personas sin presuponer que son racionales. Es parte de nuestra naturaleza el explicar incluso el desfase entre lo que una persona hace y lo que debería hacer, es decir, explicar conductas erróneas o incoherentes, creencias falsas o inconsistentes, a partir de una base de racionalidad general. Esta presunción de racionalidad es la única forma de detectar desviaciones parciales. ${ }^{3}$

Aquellos autores que ponen el énfasis en nuestro fracaso en alcanzar la racionalidad total, se ocupan de un tema diferente. Así, Stich ha criticado la idea de racionalidad como optimización dirigiendo su crítica hacia la que él llama "tesis Davidson / Dennett" de que el mal razonamiento es imposible (Stich, 1990, p. 10). Confiesa Stich que, como consecuencia del estudio de datos de la psicología empírica, sus reservas acerca de la viabilidad de dos de los tres proyectos tradicionales de la epistemología (la explicación de lo que es el 'conocimiento' y la respuesta a los argumentos escépticos) se han extendido al tercero: la evaluación y crítica de las estrategias de investigación. Los

\footnotetext{
3 "El hecho es que la posibilidad de la irracionalidad depende de un alto grado de racionalidad. La irracionalidad no es una mera ausencia de razón, sino una enfermedad o perturbación de la razón” (Davidson, 1982, p. 321).
} 
experimentos sobre la corrección del razonamiento ${ }^{4}$ muestran que a menudo somos muy deficientes incluso en la resolución de problemas deductivos fáciles, por lo que Stich se pregunta si es en principio posible distinguir entre razonamientos buenos y malos. El principal objetivo de su crítica es Dennett al que asocia, correctamente en este aspecto de su filosofía, con Davidson. Según Stich, ambos autores mantienen que el mal razonamiento es imposible porque la racionalidad es un requisito de la interpretación. Aquí Stich (como en su anterior debate con Dennett: ver Dennett, 1979 y 1981; Stich, 1981) confunde dos formas diferentes de entender la racionalidad. Una de ellas, de la que él se ocupa, podría llamarse 'racionalidad descriptiva'. La otra forma de entenderla, la que cimienta la idea de que la racionalidad es necesaria para la interpretación, podría llamarse 'racionalidad normativa'. (Sigo así el uso de términos elegido por

Stich en su discusión del contraste entre un monismo cognitivo descriptivo y otro normativo: el segundo conlleva la idea de que necesitamos presuponer que una persona a la que estamos interpretando comparte con nosotros, los intérpretes, lo que consideramos que es un conjunto consistente de creencias, el primero lo caracteriza Stich por medio de la afirmación de que sólo hay un conjunto posible de creencias consistentes.) La racionalidad descriptiva es la racionalidad de un sujeto que elige (con éxito) actuar de acuerdo con la aplicación de las leyes de la lógica deductiva a su conocimiento. cuando una persona deja de hacer esto, podemos llamar irracional a su conducta. Por otra parte, la racionalidad normativa no se opone a la irracionalidad, sino a la carencia de racionalidad, i.e., la ausencia de una base desde la que juzgar el carácter racional o irracional (descriptivo) de una acción. Así, el enfoque

\footnotetext{
${ }^{4}$ Por ejemplo, la tarea de selección de Wason, en la que un gran número de sujetos fracasan en la resolución de problemas que involucran aplicaciones simples del modus ponens y modus tollens y cuyo éxito aumenta considerablemente si la tarea se sitúa en un contexto familiar (Johnson-Laird and Wason, 1977), o la frecuencia de la falacia de la conjunción, cometida por un número considerable de sujetos, que encuentran que " $p$ \& q" es más probable que "p" cuando "q" les parece mucho más probable que "p": e.g., encuentran más probable que "Almodóvar será el próximo presidente del gobierno y Rafael Nadal ganará Roland Garros" que "Almodóvar será el próximo presidente del gobierno" (Tversky and Kahneman, 1983). Ver Stich (1990, pp. 4-9).
} 
interpretativo subraya el elemento racional en la conducta interpretada (el elemento que la intérprete asume que hay en común entre ella y quien está siendo interpretado) sin que este énfasis impida que la interpretación incluya censuras cognitivas de los casos de irracionalidad empírica.

Necesitamos racionalizar para encontrar errores en la argumentación. Cuando, por ejemplo, un miembro del gobierno dice "el año pasado la inflación fue inferior al 2.5 por ciento, la menor de los últimos 25 años: nuestra política económica está siendo muy exitosa", no pensamos necesariamente que su razonamiento sigue reglas distintas al nuestro, o ningunas: podemos pensar que la hablante está deliberadamente ocultando hechos que desacreditarían su inferencia (por ejemplo, una inflación muy baja en los países del entorno económico), o que está intentando engañar a la audiencia, o que desconoce lo que está ocurriendo.

Según Stich es una consecuencia de la tesis Davidson / Dennett que del monismo cognitivo normativo se sigue el monismo descriptivo y, por tanto, este último no sería una tesis empírica. ${ }^{5}$ Sin embargo, el monismo normativo no está comprometido con la idea de que no se den casos de irracionalidad. Con lo que está comprometido es con la tesis de que si alguien nos presenta tal cantidad de estos casos como para hacer imposible retener la presunción de racionalidad, estaremos obligados a recurrir a otros niveles de análisis (neurología, química). Lo que Davidson mantiene, y quizá también Dennett, aunque este último es más resbaladizo ${ }^{6}$, es que si hubiera visiones del mundo que se resistieran a nuestra interpretación, no seríamos capaces de reconocerlas y no tendríamos razón alguna para llamarlas visiones del mundo. O la existencia de sistemas cognitivos alternativos defendida por Stich puede

\footnotetext{
${ }^{5}$ Stich se opone a otras dos líneas de argumentación: la idea de que la evolución produce organismos que son una buena aproximación a sistemas óptimamente diseñados y que un sistema así diseñado es racional, y lo que Stich llama el argumento de Cohen, según el cual es en el dominio de la competencia y no en el de la actuación donde la inferencia ha de ser normativamente impecable. No me detendré en esta discusión. Ver Cohen 1981 y 1993, Dennett 1987 y 1995, y Davidson 1990.

${ }^{6}$ Sin ir más lejos, Dennett parece deslizarse desde una defensa del monismo descriptivo al normativo en la transición entre Dennett 1971 y 1979, por un lado, y Dennett 1981.
} 
ser comprendida desde el nuestro, o llamarlos sistemas cognitivos será meramente darles un título honorífico.

La racionalidad de la que Davidson y Dennett hablan no es la racionalidad que encontramos cuando intentamos comprender el sentido de la conducta de las personas. Es la racionalidad que tenemos que presuponer para ser capaces de ver la conducta como algo que las personas hacen y no meramente como algo que les sucede. Como ocurre en el debate en la biología teórica entre adaptacionistas y antiadaptacionistas (con Maynard Smith y el propio Dennett entre los primeros, y Gould y Lewontin entre los segundos; ver Maynard Smith 1958, capítulo 1, Dennett 1995 y Gould y Lewontin 1979), cada parte pone el acento en un aspecto de la imagen global, cuando ambos aspectos no son necesariamente incompatibles. Si buscamos soluciones óptimas para problemas conductuales (o evolucionistas, en el caso de Dennett) tenemos que estar dispuestos a conformarnos con encontrar soluciones meramente adecuadas: no podemos olvidar las limitaciones que hacen la perfección inalcanzable. Pero centrarse excesivamente en estas limitaciones puede conducirnos a ignorar el hecho de que sólo podemos entenderlas sobre la base de una concepción general de la racionalidad o de la optimización.

Stich subraya el fracaso individual en alcanzar la racionalidad ideal y critica el enfoque intencional de Dennett por asumir esta última. La respuesta a esta acusación llama la atención sobre la necesidad de una base de racionalidad que dé sentido a la conducta irracional (siguiendo la idea de Davidson de que necesitamos un acuerdo general para comprender el desacuerdo puntual). Esta respuesta asume que el enfoque intencional o la psicología popular no son una teoría sobre el mundo y la conducta humana, sino una actitud, una perspectiva, un punto de partida.

\subsection{STRAWSON Y LA METAFÍSICA POSTKANTIANA}

¿En qué consiste esta actitud, si no es una teoría? ¿Cómo puede articularse la idea de que las categorías de sentido común de persona u objeto material son primitivas con respecto a las categorías de estado mental o de impresión sensorial? En esta sección exploraré los argumentos de varios autores y, en particular, el original uso que Strawson hace de la filosofía kantiana, para dar respuesta a estas preguntas. La idea central es que la estrategia intencional no es una teoría que explica nomológicamente lo que los seres racionales hacen, sino que lo que caracteriza a un ser como racional es el 
que encuentre inevitable usarla para dar sentido de su propia conducta y de la de los otros usuarios. En la segunda parte de este trabajo se analizará una propuesta, debida a Wilfrid Sellars, según la cual esta estrategia intencional debe ser, en principio, reemplazable por una teoría científica, y se defenderá que tal reemplazo es sólo concebible si no se presta suficiente atención al carácter normativo de la presunción de racionalidad tal y como se ha expuesto en las páginas anteriores.

Strawson se ha esforzado a lo largo de su obra en defender un acercamiento entre las perspectivas filosóficas humeanas y kantianas. Contra los intentos racionalistas, y particularmente los de los empiristas anteriores a él, Hume sostuvo que no podemos deducir normas y razones a partir de episodios externos a la razón. No es fácil, sin embargo, encontrar en su filosofía una forma alternativa de entender el conocimiento y la naturaleza de la creencia. Strawson (1985, pp. 10-15) llama la atención sobre la tensión existente en la obra del escocés entre el escepticismo y el naturalismo. Esta tensión la reconoce el propio Hume con desesperación poética al final del primer libro de su Tratado de la naturaleza bumana. Hume nos dice allí que

esa pregunta [si todo es inseguro y nuestro juicio no posee en ninguna cosa medida ninguna ni de verdad ni de falsedad] es completamente superflua, y (...) ni yo ni ninguna otra persona ha sido nunca sincera y constantemente de esa opinión. La naturaleza, por medio de una absoluta e incontrolable necesidad, nos ha determinado a realizar juicios exactamente igual que a respirar y a sentir; (...) todos nuestros razonamientos concernientes a causas y efectos no se derivan sino de la costumbre, y (...) la creencia es más propiamente un acto de la parte sensitiva de nuestra naturaleza que de la cogitativa (Hume 1739-40, p. 183; trad.: F. Duque).

Así, dogmatismo y escepticismo son del mismo tipo, aunque opuestos en su operación y tendencia (ibid., 187; recuérdese la cita anterior, a propósito del pensamiento animal, en la que Hume encontraba igualmente ridículo negar una verdad obvia que insistir demasiado en ella). Aquí podemos ver como el naturalismo de Hume adelanta la solución trascendental de Kant al problema del conocimiento. Todo lo que hace falta para pasar del uno a la otra es mostrar que la distinción entre las partes 'sensitivas' y 'cogitativas' de nuestra naturaleza no es tan radical como la filosofía prekantiana pensaba. Si es posible defender que al menos algunas de nuestras herramientas cognitivas operan ya en nuestra experiencia del mundo y que la separación entre la contribución del 
mundo y la del sujeto es, a lo sumo, una separación explicativa y no sustancial, el escepticismo pierde mucha de su fuerza.

Strawson subraya de esta forma el parecido entre Hume y Kant, aunque el paralelismo es, de acuerdo con él, tenue:

Mientras que Hume hace referencia a una inevitable disposición natural a

la creencia, Kant proporciona un argumento (un argumento trascendental) para mostrar que lo que en el nivel empírico es correctamente considerado como conocimiento empírico de un mundo externo con objetos gobernados por leyes, es condición necesaria de la autoconciencia, del conocimiento de nuestros estados internos. $\mathrm{Y}$ - una diferencia aún más notable-mientras que, en el nivel crítico, Hume nos deja con un escepticismo irrefutado, Kant nos ofrece su propia variedad de idealismo (Strawson, 1985, p. 13).

Strawson conecta el naturalismo de Hume con algunas anotaciones de Wittgenstein en Sobre la certeza. Wittgenstein habla de algunas convicciones o creencias como si se encontraran más allá de estar o no justificadas, como algo animal (Wittgenstein, 1969, para. 359). Llega a distinguir entre las proposiciones que están sujetas a la prueba empírica y aquéllas que forman el andamio o estructura de nuestro pensamiento, negándole a veces a estas últimas el estatuto de proposiciones. ${ }^{7}$. Mientras que Hume apela a la Naturaleza como la implantadora de las convicciones naturales, y las limita a la existencia del cuerpo y a la fiabilidad general de la formación inductiva de creencias, Wittgenstein piensa que la estructura es más dinámica y reemplaza a la naturaleza por el aprendizaje de actividades y prácticas sociales. Para ambos filósofos, por otra parte, estas creencias básicas están "fuera de nuestra competencia crítica y racional en la medida en que definen, o ayudan a definir, el área en la que esa competencia se ejerce" (Strawson 1985, p. 19). Esta forma de poner el énfasis en el carácter de presunción normativa que una cierta estructura racional tiene para nuestro conocimiento del mundo enlaza con la tesis Davidson / Dennett defendida en la sección anterior.

\footnotetext{
${ }^{7}$ Ver, por ejemplo, para. 200 y 205, donde las proposiciones se caracterizan por ser verdaderas o falsas, y el que puedan ser verdaderas o falsas depende de que puedan fundamentarse, donde el fundamento no puede ser ni verdadero ni falso.
} 
Lo que define el 'naturalismo no reductivo' que Strawson encuentra en Wittgenstein es que subraya el carácter inevitable, natural, de nuestra actitud moral, fenomenológica y objetivista. Por contraste, el 'naturalismo reductivo' mantiene que la visión científica de los humanos y su comportamiento mina la validez de dichas actitudes y las reduce a la categoría de ilusiones. Contra el naturalismo reductivo Strawson defiende la idea de que tenemos una "disposición muy arraigada a considerar que los cuerpos ordinarios, esto es, los objetos físicos comunes, poseen propiedades fenomenológicas y a considerar a los agentes humanos y sus acciones como objetos adecuados de actitudes morales, esto es, como portadores de atributos morales y éticos" (ibid., p. 51). Por otra parte, la perspectiva científica parece proporcionarnos un marco desde el que despojar a los objetos (y a las personas) de sus atributos morales y fenoménicos. Sin embargo, la tentación de pensar que este marco nos ofrece la única concepción correcta del mundo (i.e., la tentación de caer en el naturalismo reductivo) debe ser evitada. Primero, porque dar un enfoque no intencional y no fenomenológico de los "movimientos" de los humanos no es explicar la conducta humana. Cualquier explicación de una acción de una persona debe hacer referencia a estados mentales (percepciones, creencias, deseos). Y segundo, y más importante, porque la perspectiva científica no es una alternativa a, ni un sustituto de, la perspectiva natural, sino una región de ella (si el lector es paciente, encontrará más abajo argumentos para sostener estas dos afirmaciones).

La posición de Strawson se enmarca dentro de una distinción general entre dos formas de enfocar la metafísica, que nuestro autor llama descriptiva y revisionista. La primera tiene como objetivo describir la estructura real de nuestro pensamiento acerca del mundo, mientras que la metafísica revisionista persigue la mejora de esa estructura. La metafísica descriptiva sólo se diferencia del análisis lógico o conceptual en su alcance y generalidad, no en su intención. La primera parte del libro Individuos pretende demostrar, dentro de la línea descriptiva y no revisionista elegida por Strawson, que los objetos materiales y las personas ocupan un lugar prioritario entre los particulares, es decir, que los conceptos de otros particulares son secundarios con respecto a los conceptos aplicados a objetos y personas. Strawson menciona entre los particulares que dependen para su individuación de la individuación de objetos y personas, sin que la individuación de estos últimos dependa de aquellos, a los datos de los sentidos (sense-data), a las entidades teóricas / no observables y a los eventos. Los cuerpos juegan un papel predominante en la constitución de nuestras 
habilidades identificatorias porque su carácter encaja perfectamente con los requisitos de nuestro esquema conceptual: la continuidad espacio-temporal y la observabilidad: "Pensamos que el mundo contiene cosas específicas, algunas de las cuales son independientes de nosotros" (Strawson, 1959, p. 15). A veces la identificación de particulares de una clase depende de la identificación de particulares de otra. Esto sugiere que la identificabilidad de los particulares de una clase puede depender en general de la identificabilidad de particulares de otros tipo, lo que significaría que es una característica general de nuestro esquema conceptual el que los particulares del último tipo son ontológicamente anteriores con respecto a los particulares del primero. ${ }^{8}$ Según Strawson, el marco de relaciones espacio-temporales posee una extensión y generalidad única para organizar nuestro pensamiento individuador sobre particulares. Sólo dentro de este marco tiene sentido hablar de identificación errónea o falsedad. Desacuerdos sobre la identificación de particulares "sólo son posibles en el contexto de un acuerdo más general, aunque menos estricto, acerca de las relaciones de esas entidades con otras sobre las que estamos de acuerdo" (ibid., p. 38).

Strawson ofrece en el capítulo 2 de Individuos una versión ligeramente debilitada de la tesis kantiana según la cual el espacio es una condición necesaria para la existencia de experiencia objetiva. "El carácter de particulares básicos de los cuerpos materiales ¿es condición necesaria del conocimiento de

\footnotetext{
${ }^{8}$ Quizá resulte extraño que de la prioridad en la identificación se deduzca una prioridad ontológica en lugar de una meramente epistemológica. A mi entender opera aquí una asunción que se hace explícita, por ejemplo, en Mind and World de John McDowell (1994): la materia que constituye el mundo es ya conceptual y por ello epistemología y ontología son interdependientes (McDowell argumenta que esta es la esencia hegeliana de la lectura que Strawson hace de Kant en Los limites del sentido (1966): ver abajo). Esta cita puede aclarar las cosas: "No me parece objetable usar la expresión 'ontológicamente anterior' de forma tal que la afirmación de que los cuerpos materiales son los particulares básicos de nuestro esquema conceptual sea equivalente a la afirmación de que los cuerpos materiales son ontológicamente anteriores, en ese esquema, a otros tipos de particulares" (Strawson, 1959, p. 59).

${ }^{9}$ Con respecto a esta interdependencia de epistemología y ontología, Strawson y Davidson son compañeros de viaje: ver Davidson 1974 y 1977 para los detalles de su argumento contra posibilidad de separar los sistemas de conceptos del contenido empírico o del mundo sobre el que tratan.
}

Análisis. Revista de investigación filosófica, Vol. 1, nº 1, 2014 
particulares objetivos? (...) ¿Podría haber un esquema que proporcionara un sistema de particulares objetivos que no fuera plenamente espacial?" (ibid., p. 62). Para apoyar su tesis nos invita a imaginar un ser cuya experiencia es puramente auditiva e intenta demostrar que no habría lugar para conceptos espaciales, y por ello objetivos, en este tipo de experiencia. La pregunta a la que Strawson intenta responder es: "¿Podría un ser cuya experiencia fuera puramente auditiva [i.e., no espacial] tener un esquema conceptual que incluyera particulares objetivos?" (ibid., p. 66). Esto es importante porque "no podemos comunicarnos acerca de lo privado si no podemos comunicarnos acerca de lo público" (ibid., p. 68). La cuestión sobre la relación entre los conceptos espaciales y la objetividad está relacionada con otra más importante y general: ¿podría haber un ser con una forma no solipsista de conciencia (es decir, un ser que pudiera distinguir entre, por una parte, ella y sus estados y, por otra, cosas que no son ella ni sus estados) con una experiencia no espacial? $^{10}$

Los cuerpos materiales son los particulares básicos por su carácter tridimensional y su permanencia a través del tiempo, lo que los hace accesibles a nuestro aparato perceptual. Otros particulares dependen de ellos para su identificación. El tipo de dependencia de la que Strawson habla se ve claramente representada por la dependencia de la identificación de 'particulares privados' (datos de los sentidos) con respecto a la identificación de la clase de personas. "La referencia [cuando menos] implícita a una persona particular es, sin embargo, esencial para la fuerza identificadora de las frases demostrativas

\footnotetext{
${ }^{10}$ Gareth Evans explica la afirmación de Strawson de que el espacio es necesario para la experiencia objetiva en los siguientes términos: para tener el concepto de objetividad una criatura tiene que ser capaz de comprender la hipótesis de que los fenómenos de los que tiene experiencia podrían suceder sin ser percibidos. Evans distingue dos clases de propiedades que un objeto puede tener: "aquellas propiedades que son disposiciones a afectar a seres sensibles con ciertas experiencias" (Evans, 1980, p. 95) ('propiedades sensoriales o secundarias') y 'propiedades no sensoriales o primarias'. Las propiedades constitutivas de la idea de una sustancia material como 'materia en el espacio' son primarias, e incluyen posición, tamaño, forma, movimiento, masa, peso, etc. (esto es, las propiedades estudiadas por las ciencias físicas). Para captar este tipo de propiedades necesitamos una teoría y la idea de un marco espacial unificado donde el propio cuerpo y los objetos que las instancian puedan ser localizados.
} 
referentes a experiencias privadas" (ibid., p. 42). Otra clase de particulares condenados a la dependencia identificadora es la de los 'constructos teóricos', los objetos inobservables. Su identificación depende de la de objetos observables. Volveré a la idea de que las entidades teóricas dependen asimétricamente de los objetos de la imagen manifiesta en mi discusión de Sellars en la segunda parte de este trabajo.

Siguiendo a Kant, Strawson mantiene que la autoadscripción de estados depende de la capacidad de adscribir tales estados a otros: "es una condición necesaria de la adscripción de estados de conciencia, de experiencias, a uno mismo el que uno se los adscriba, o esté dispuesto a hacerlo, a otros que no son uno mismo" (Strawson, 1959, p. 99). ${ }^{11}$

Lo que tenemos que reconocer (...) es el carácter primitivo del concepto de persona. Lo que quiero decir con el concepto de persona es el concepto de un tipo de entidad tal que tanto predicados que adscriben estados de conciencia como predicados que adscriben características corporales, situación física, etc., son igualmente aplicables a un individuo determinado de un tipo determinado (ibid., p. 101-2).

Strawson argumenta que la experiencia perceptiva juega el papel unificador que hace que los dos tipos de predicados sean aplicables a la misma entidad: la experiencia depende de hechos acerca del cuerpo del que percibe, sin que esta dependencia impida la adscripción de propiedades corporales al que percibe en lugar de a su cuerpo. Al mismo tiempo, existe una continuidad entre los estados de experiencia y otros estados de conciencia. Pero, por otra parte, la idea cartesiana de una conciencia individual pura no puede ser el concepto primitivo desde el que se deriva el concepto de persona porque el primero se explica en términos del segundo. La palabra 'yo' no puede referir a un sujeto puro; refiere a una persona entre otras: "El concepto de persona no puede ser analizado como un cuerpo animado ni como un alma encarnada (embodied)" (ibid., p. 103). Los predicados aplicables a personas pueden ser autoadscritos sólo si pueden ser adscritos a otros. En su uso se pueden observar tres aspectos: la autoadscripción, la adscripción a otros, y la habilidad de ver a los otros como autoadscriptores y adscriptores a terceros. Más aún,

${ }^{11}$ Cf. Hegel: "La autoconciencia sólo alcanza su satisfacción en otra autoconciencia"; Hegel (1807, p. 112). 
parece que necesitamos ser sensibles a este tercer aspecto para adquirir la capacidad de usar los predicados. El reconocimiento de este hecho impide la aparición de problemas escépticos radicales.

Esta propuesta de Strawson y su inspiración kantiana dirigen nuestra mirada hacia la idea de que el giro antimetafísico que con frecuencia se considera característico de la filosofía del siglo XX (la idea de que este giro se debe a Nietzsche, los pragmatistas, Wittgenstein y Heidegger ha sido influyentemente defendida por, por ejemplo, Rorty; ver Rorty, 1980) se debe a Kant. Según esta interpretación sería la metafísica constructiva o revisionista la que está pasada de moda, y lo estaría desde el trabajo crítico de Kant. No es necesario decir que este trabajo está lleno de ambigüedades desafortunadas, y que la tentación de violar sus propias reglas puede observarse en distintas partes. No obstante, la mayor contribución de Kant a la filosofía fue señalar que los intentos de hablar acerca de la estructura del mundo independientemente de cualquier experiencia posible conducen a contradicciones. Esto no impidió que Kant llamara a su propio sistema "metafísica", pero deberíamos ver este sistema como metafísica descriptiva y no constructiva.

Esta distinción entre metafísica prekantiana y postkantiana la explora con agudeza van Fraasen en Laws and Simmetry (1989):

La metafísica atacada por la Crítica de Kant se caracterizaba por la convicción de que la razón puede conducirnos a la certeza (...) lógica de verdades que trascienden la experiencia. Lo máximo que uno puede conseguir con la razón sola es una deducción, a partir de las condiciones requeridas para que la conciencia sea posible, de verdades generales acerca de la estructura de la experiencia (p. 8).

Van Fraasen tiene como objetivo desacreditar la metáfora cartesiana que sitúa a la filosofía en la raíz del árbol del conocimiento, siendo la física su tronco y las ciencias especiales sus ramas, y ésta es una tarea que, desgraciadamente, no ha dejado de ser necesaria. La investigación de las condiciones trascendentales de la experiencia debería parar cuando las sombras transcendentes de lo nouménico empiezan a aparecer, y no está nada claro que Kant evitara su atracción.

Una de las mayores dificultades para comprender el trabajo de Kant es precisamente que contiene al mismo tiempo el peso de la metafísica prekantiana y la promesa de la filosofía postkantiana. Su uso de la noción de 
'noúmeno' es particularmente ilustrativa de esta tensión. Cuando Kant quiere distanciarse del escepticismo empirista opta por fundamentar (casi causalmente) las apariencias en "las cosas en sí": “(...) aunque no podemos conocer esos objetos como cosas en sí mismas, sí ha de sernos posible, al menos, pensarlos. De lo contrario, se seguiría la absurda proposición de que habría fenómeno sin nada que se manifestara." (Kant, 1781/7, Bxxvi-xxvii; trad.: P. Ribas); y "El objeto trascendental (...) sirve de base [desconocida para nosotros] a los fenómenos (...)" (ibid. A380). Pero cuando argumenta contra la tradición racionalista mantiene que las cosas en sí no son ni siquiera pensables:

De modo que, a través de la sensibilidad, no sólo conocemos la naturaleza de las cosas en sí mismas de manera confusa, sino que no la conocemos en absoluto. Desde el momento en que suprimimos nuestra condición subjetiva, el objeto representado y las propiedades que la intuición sensible le haya atribuido no se encuentran en ninguna parte, ni pueden encontrarse (...) (ibid. A44/B62).

Y también en la sección "Fenómenos y noúmenos": "Así, pues, el concepto de noúmeno no es más que un concepto límite destinado a poner coto a las pretensiones de la sensibilidad. No posee, por tanto, más que una aplicación negativa" (ibid. A255/B310-1).

Strawson ha discutido con insistencia esta tensión en su intento de salvar a Kant de sí mismo. ${ }^{12}$ Critica su idealismo trascendental: "La doctrina no mantiene meramente que no podemos tener conocimiento de una realidad supersensible. La doctrina dice que la realidad es supersensible y que no podemos tener conocimiento de ella" (Strawson, 1966, p. 38). Strawson mantiene que esta doctrina puede ser incoherente, por ejemplo cuando la aplicamos a nosotros mismos. Según ésta nos aparecemos a nosotros mismos sólo temporalmente, y no como realmente somos. Ahora bien, ¿̇ignifica esto que realmente nos aparecemos a nosotros mismos temporalmente, o que

\footnotetext{
12 Una muestra de que lo que Strawson hace es una interpretación poco ortodoxa de la filosofía kantiana puede encontrarse en los iluminadores trabajos de, por ejemplo, Allison (1983) y Langton (1998), que defienden respectivamente una versión moderada del idealismo trascendental y el humilde compromiso de Kant con la existencia de las cosas en sí.
} 
realmente nos aparecemos a nosotros mismos temporalmente? Pero no está claro que pueda responderse a la pregunta "¿qué significa "aparecerse realmente"?

El rechazo de Strawson del idealismo trascendental es consecuencia de la idea de que éste entraña una invocación (aunque sólo fuera negativa) a las cosas en sí mismas para dar sentido a la experiencia y al conocimiento. Sin embargo, el trabajo de Strawson insiste en la interdependencia del mundo y nuestras formas de pensar sobre él, y en este sentido permanece dentro de la tradición idealista. Pero es éste un idealismo inocente que intenta evitar los errores de las variedades escéptica, berkeleyana y trascendental.

En esta sección he discutido la posibilidad de ofrecer una concepción exhaustivamente descriptiva de la racionalidad, tendente a sustituir cualquier presunción normativa que la interpretación de la conducta racional pueda conllevar por una explicación nomológica de la misma. Contra esta posibilidad he argumentado con Strawson que hacer esto supondría cambiar de tema, y que las explicaciones que relacionan causalmente estados metales, datos de los sentidos y estados de cosas dependen del concepto primitivo de persona. En la segunda parte de este trabajo extenderé esta prioridad conceptual para oponerme a las conclusiones eliminativistas que Sellars extrae de un argumento complementario al de Strawson, el que cuestiona la fundamentación del conocimiento en algo dado.

\section{SELLARS Y LA EPISTEMOLOGÍA POSTKANTIANA}

\section{1. EL MITO DE LO DADO}

En la primera parte de este trabajo hemos como Strawson hace uso de algunas ideas kantianas para rechazar la concepción de un mundo cuya naturaleza es en principio independiente de nuestro conocimiento de ella y para defender la prioridad de la noción de persona con respecto a la noción de mente. A continuación discutiré la conversa de este rechazo: una crítica de la posibilidad de ofrecer una fundamentación de nuestro conocimiento apoyada en algo externo a la razón, en algo "dado". En su clásico artículo "Empiricism and the philosophy of mind" (1963a) Sellars pone en cuestión los intentos de buscar los cimientos del edificio del conocimiento en cualquier forma de conciencia preepistémica. Una de las premisas implícitas en su ataque a estos intentos es la distinción entre dos tipos de conciencia: conciencia en el sentido de simplemente estar despierto y conciencia entendida como autoconciencia. 
Según Sellars, la segunda es condición suficiente del conocimiento, mientras que la primera sólo es necesaria.

En la jerga hegeliana, que no hace violencia al espíritu del artículo: el conocimiento robusto sólo es posible cuando la conciencia del yo y la conciencia del mundo están integradas; conocemos el mundo conociéndonos a nosotros mismos, y nos conocemos a nosotros mismos conociendo al mundo. La interacción desnuda, preconceptual, con el mundo (por ejemplo, al retirar rápidamente una mano al quemarse) no puede tener el carácter de conocimiento porque el conocimiento está sujeto a revisabilidad racional, lo que equivale a decir que es conceptual. El aprendizaje de un lenguaje público es nuestra forma de llegar a ser racionales: al adquirir un lenguaje público también adquirimos una concepción de nosotros mismos, un mundo poblado por objetos públicos y, en última instancia, una mente.

La crítica de Sellars de la idea de lo dado está dirigida explícitamente a las teorías del conocimiento que hacen uso de la noción de datos de los sentidos. El concepto clásico de dato de los sentidos surge de la combinación de dos tipos de ideas: (1) la idea de que existen ciertos episodios internos, p.e., sensaciones de rojo, que pueden acaecer a animales sin ningún proceso previo de aprendizaje y formación de conceptos; y (2) la idea de que hay algunos episodios internos que consisten en conocer no inferencialmente que las cosas son, por ejemplo, rojas, y que tales episodios son necesarios para cualquier forma de conocimiento empírico.

La adopción de (1) es consecuencia del intento de explicar la percepción sensorial científicamente. Las sensaciones postuladas por (1) son producidas "en su mayor parte" (Sellars, 1963a, p. 133) por la presencia de un objeto físico adecuado en la proximidad del que percibe, y mientras que los bebés pueden tenerlas sin "ver que" o "parecer que ven que", esto sí ocurre en los adultos cuando tales sensaciones son causadas en ellos. "No hay razón para suponer que tener una sensación de un triángulo rojo es un hecho cognitivo o epistémico." (ibid., 133). Existe la tentación de asimilar las sensaciones y los pensamientos y atribuir a las primeras la intencionalidad de los últimos. Una forma de evitar esta asimilación es tomar a las sensaciones como sui generis, ni epistémicas ni físicas. Pero esto conduce a una línea de pensamiento desafortunada: dado que las experiencias, tales como ver ostensiblemente una superficie física roja, a veces no son verídicas, la fundamentación del conocimiento empírico no puede reposar en ellas; por ello esta fundamentación tiene que apoyarse en otra cosa, sensaciones, que se ven 
asimiladas al pensamiento en su intencionalidad (y, por tanto, convertidas en epistémicas) y que, por hipótesis, se encuentran mucho más íntimamente relacionadas con los procesos mentales que con los objetos físicos externos. Sellars se opone tanto a la asimilación de sensación y pensamiento como al hecho de que no se tenga en cuenta la posibilidad de que las sensaciones puedan ser no verídicas (una posibilidad que debe existir si queremos aplicarles el calificativo "verídico").

En su crítica, Sellars señala que no podemos mantener que los productos de una capacidad innata (nuestra recepción pasiva de inputs del mundo) puedan entrañar algo (conocimiento) que es el producto de una capacidad adquirida (la racionalidad, resultado del aprendizaje lingüístico). Lo que lleva al empirismo a este callejón sin salida es mezclar un enfoque causal (que se ocupa de las condiciones necesarias y posibilitadoras del conocimiento, tales como tener un cerebro o recibir estímulos en las terminaciones nerviosas, i.e., ser una criatura sintiente) con un enfoque racional (que se ocupa de las relaciones conceptuales y de justificación entre estados mentales, i.e., se ocupa de la sapiencia). $\mathrm{Y}$ al igual que estar despierto no es suficiente para ser consciente, tener episodios neuronales no es suficiente para tener conocimiento. El conocimiento depende en parte del mundo y de cánones públicos de justificación. Esto no quiere decir que el estudio de los mecanismos causales que hacen posible la racionalidad, la caracterización de éstos en términos preepistémicos, y el análisis de su relación (causal) con episodios epistémicos sea una pérdida de tiempo. Pero sería una confusión esperar que esta línea de trabajo nos ofreciera los elementos para explicar la justificación de nuestras creencias en términos de la actividad neuronal que las hace posibles. Las impresiones sensoriales, los datos de los sentidos, el contenido no conceptual están sujetos a la crítica del mito de lo dado sólo si se los pone a cumplir una labor epistemológica. Por lo demás, son conceptos en principio perfectamente respetables en filosofía de la psicología y de las ciencias cognitivas.

Paralelamente a la crítica sellarsiana del mito de lo dado centrada en los datos sensoriales, son de interés las críticas que McDowell hace tanto de la tentación de hacer un uso epistemológico de la noción de contenido no conceptual (ver McDowell, 1994a, especialmente la conferencia III y el apéndice II) como de la apelación a estados subpersonales como constitutivos de los estados mentales personales (creencias, deseos, percepciones, etc.; ver 
McDowell, 1994b dirigido explícitamente contra el artículo de Dennett "Towards a cognitive theory of consciousness"; Dennett, 1978). ${ }^{13}$

De acuerdo con Dennett, los contenidos que le adscribimos a los estados mentales de las personas son parte del contenido subpersonal (esto es, parte del contenido de los estados de los sistemas internos-cerebrales, del sistema nervioso central—de procesamiento de la información), la parte a la que el sujeto tiene acceso. Sin embargo, el intento de establecer un paralelismo entre estados personales y subpersonales está basado en un error: hablando estrictamente, el contenido que se atribuye a los estados internos no es contenido propiamente dicho. Una reconstrucción de los estados mentales con contenido de una persona en términos, por ejemplo, de la manipulación sintáctica por parte de nuestra maquinaria interna, no nos permitirá explicar las propiedades relevantes de los estados personales con contenido. Los estados mentales son intencionales, semánticos y racionalmente revisables. Si intentamos dar cuenta de estas propiedades apelando exclusivamente a estados subpersonales, nuestra teoría tendrá que enfrentarse a la clásica crítica humeana a los intentos de fundamentar nuestras percepciones de objetos, nuestras experiencias, en meras sensaciones o impresiones. Sólo si consideramos a la experiencia, desde el principio y de forma inanalizable, como un encuentro genuino con objetos, nos estará permitido elevar el edificio del conocimiento a partir de ella. Si, por el contrario, partimos de la idea de que existe una frontera entre nuestra mente conceptual por un lado y un mundo que se presenta a ella no conceptualmente por otro, nos arriesgamos a caer en el mito de lo dado y a ser víctimas de la crítica humeana: no hay un camino racionalmente justificable que vaya desde la experiencia entendida como algo no objetivo hasta el pensamiento entendido como pensamiento acerca del mundo. Es probable que sea necesario estudiar la relación entre el cerebro o el sistema nervioso y lo que hay fuera de él como si ambos elementos estuvieran separados por una frontera, pero esta separación sólo será de interés para las ciencias cognitivas y ahí es donde su importancia filosófica termina. Una explicación de los mecanismos posibilitadores de la racionalidad no es una explicación de la

\footnotetext{
${ }^{13}$ He desarrollado esta segunda crítica, en el contexto de un argumento contra la reductibilidad de la noción de agente en biología, en Pinedo \& Noble (2008).
} 
racionalidad. En términos epistemológicos, si abandonamos la referencia a personas y a sus razones ya no nos será posible reencontrarlas. ${ }^{14}$

McDowell se enfrenta también a la tesis de que al menos parte del contenido de la experiencia no es conceptual, influyentemente defendida por Gareth Evans (ver Evans 1982, especialmente capítulos 5 a 7). La oposición de McDowell a la noción de contenido no conceptual en sus usos en epistemología y fenomenología puede parecer una batalla sobre términos, especialmente dada su coincidencia con Evans en la identificación de lo conceptual con el reino de los sentidos fregeanos (es decir, con el reino de los modos de presentación de las cosas o de las maneras de conocer las cosas; ver McDowell 1994a, conferencia V) y dada también la concepción del sentido como dependiente de los objetos que ambos comparten (ver, especialmente, McDowell 1977 y Evans 1981 y 1982, capítulos 3 y 6). La asociación entre conceptual y objetivo que se sigue de la teoría del sentido de McDowell junto con las estrictas condiciones que el contenido debe cumplir para ejercer un papel justificatorio (especialmente el que tal contenido deba ser, en principio, justificable para ser justificador) implican que las condiciones de corrección de las experiencias sólo pueden ser condiciones de verdad, donde la verdad se entiende como una noción normativa y racional. Me limitaré a apuntar, para terminar este paréntesis, que la concepción de la experiencia de McDowell permitiría evitar la tensión existente dentro de la obra de Davidson entre el normativismo de su teoría de la interpretación por un lado y el reduccionismo de su monismo anómalo. Esta tensión es consecuencia de asignar un papel meramente causal a la experiencia para evitar la dicotomía dogmática entre esquema conceptual y contenido empírico, dicotomía hermana del mito de lo dado. Ver Davidson 1970 y 1974, así como Child 1994 para un certero diagnóstico de esta tensión. ${ }^{15}$

Otra forma de expresar la idea de Sellars, que él mismo usa y con la que tanto Strawson como McDowell estarían de acuerdo, es decir que los conceptos referentes a propiedades de objetos públicos son anteriores a los

\footnotetext{
${ }^{14}$ Ver también McDowell (1985, p. 397 y n.29).

${ }^{15}$ En Pinedo (2006) pongo en cuestión la compatibilidad de la versión de Davidson del argumento contra el mito de lo dado (Davidson, 1974) con su monismo anómalo.
} 
conceptos aplicados a las apariencias: "De hecho, he estado manteniendo que ser rojo es lógicamente anterior, es una noción lógicamente más simple, que parecer rojo" (Sellars, 1963a, p. 142). No podemos cimentar nuestro conocimiento del mundo en nuestro conocimiento de estados internos, porque éste presupone aquél. Sin embargo, esto no conduce a Sellars a negar todo papel a los episodios internos. De hecho Sellars incluso reconoce un papel epistemológico para estos episodios. Pero nuestros informes acerca de ellos, aún cuando sean no inferenciales y observacionales, lo son en el mismo sentido en el que los informes sobre moléculas podrían serlo: las impresiones sensoriales son entidades teóricas, y aprendemos a usar los modelos teóricos a los que pertenecen sólo después de haber adquirido la 'imagen manifiesta' de objetos públicos en el espacio y el tiempo.

Una de las formas adoptadas por el mito es la afirmación de que hay una estructura de hechos tales que no sólo cada hecho puede ser conocido no inferencialmente sin presuponer ningún otro conocimiento, sino que ese conocimiento no inferencial es el tribunal al que ha de hacer frente cualquier afirmación acerca del mundo. Sellars señala que es una característica central del mito identificar "no inferencial" con "independiente de todo otro conocimiento". Robert Brandom (1997) lo explica diciendo que Sellars acepta el carácter no inferencial de algún conocimiento, e incluso acepta que este conocimiento no inferencial sea el tribunal del conocimiento empírico, pero no que haya conocimiento que no presuponga ningún otro conocimiento. Los conceptos que pueden ser usados para hacer informes no inferenciales deben ser también accesibles para su aplicación inferencial, como conclusiones de inferencias cuyas premisas sean usos no inferenciales de otros conceptos.

Sellars mantiene que el fundamentismo epistemológico nos obliga a elegir entre empirismo (todo el conocimiento descansa en la experiencia, que no descansa en nada) y coherentismo: "Ninguno de los dos funciona. Ya que el conocimiento empírico, como su extensión sofisticada, la ciencia, es racional, no porque tenga un fundamento sino por es una empresa autocorrectora que puede poner cualquier afirmación en duda, pero no todas al mismo tiempo" (Sellars, 1963a, p. 170).

\section{2. REALISMO CIENTÍFICO}

La alternativa sellarsiana al fundamentismo de lo dado es el realismo científico, que incluye el realismo con respecto a las impresiones sensoriales. 
Pero las impresiones no son ya entidades inmediatamente accesibles al sujeto, sino constructos teóricos. Podemos ofrecer un enfoque causal de la percepción en términos de impresiones sensoriales porque éstas juegan un papel en nuestra teoría científica de la percepción. Esto significaría el final de la epistemología. Ahora bien, la imagen manifiesta no va a desvanecerse así como así. No podemos aislar la ciencia del resto del conocimiento humano. Pero, por encima de esto, y explotando una metáfora de Sellars, la ciencia no es una península de la concepción del mundo de sentido común, sino más bien una provincia de ésta. Y si, alternativamente, queremos ser humildes sobre las posibilidades de nuestro conocimiento y afirmar que éste es relativo a nuestro limitado aparato cognitivo, ${ }^{16}$ la ciencia no puede ser una excepción. No puede mantenerse que nuestra experiencia primitiva de libertad de acción y pensamiento es el resultado de nuestras limitaciones, mientras que las teorías filosóficas fisicistas y deterministas están exentas de esta dificultad.

Ciertos episodios en las vidas de las personas, tales como conocer, están situados en el "espacio lógico de las razones", en expresión de Sellars, y el aparato conceptual que usamos para situarlos allí no puede reducirse a ningún aparato conceptual que no las sitúe en el espacio de las razones: la caracterización de hechos epistémicos debe distinguirse de la caracterización de hechos naturales (en el sentido que natural tiene en la expresión "ciencias naturales") para evitar caer en una versión de la falacia naturalista, i.e., lo que Sellars llama el mito de lo dado.

Según McDowell (1998, conferencia 1) la capacidad de ser sujeto de episodios epistémicos se usa, en una concepción kantiana, principalmente al hacer juicios. Incluso los juicios que no son el resultado de nuestra decisión libre acerca de qué pensar dependen de esta capacidad. Sellars está de acuerdo con esto: para que algo sea un juicio, un episodio de conocimiento, deber ser, en principio, justificable. Más exactamente, uno debe ser capaz de justificar lo que uno dice. Las cosas le parecen a uno así y asá sólo porque ha adquirido un

\footnotetext{
${ }^{16}$ La idea de que existe un cierre cognitivo, es decir, la tesis de que nuestro carácter natural implica que nuestra inteligencia tiene un determinado alcance y límite, y que tanto la inteligencia como la conciencia pueden estar fuera de ese límite, ha sido defendida por Fodor, pero especialmente por Chomsky (ver 1979, pp. 66-9 y 1995, pp. 2-5) y por Colin McGinn (ver 1991, pp. 1-22).
} 
lenguaje en el que los mecanismos de justificación ya están en su sitio. Esto es nuevo con respecto a Kant, aunque la apelación a la comunidad no es ajena al pensamiento kantiano, dado que la obligación y la responsabilidad moral hacia las otras personas es central en su filosofía.

El rechazo de Sellars del fundamentismo epistemológico, magníficamente expresado en su critica del mito de lo dado, subraya que el conocimiento perceptual depende de la posesión de una visión del mundo que se adquiere en sus rudimentos gracias a la pertenencia a una tradición lingüística. En este sentido, no podemos separar en Sellars su concepción de la intencionalidad (es decir, del significado objetivo de la experiencia perceptual) de su idea de que la experiencia depende de una red conceptual que la sobrepasa y sobre la que descansa. De esta forma, la epistemología y la metafísica van de la mano tanto para Sellars como para Kant. Sellars, al afirmar que el ser es anterior al parecer, hace que la epistemología dependa metodológicamente de la metafísica. La metafísica de Kant puede resumirse con el siguiente lema: "la epistemología es trascendental": esta es su forma de rechazar cualquier llamada filosófica a lo trascendente, lo nouménico. La intencionalidad y la teoría del contenido sólo pueden entenderse una vez que se abandona la idea de que sólo podemos inferir causalmente cómo son las cosas a partir de lo que parecen. Los objetos de nuestros pensamientos, sus contenidos o 'intentio', son objetos del mundo. Incluso nuestro tomarlos como lo que no son depende de que normalmente sean tomados como lo que son. Necesitamos la capacidad de pensar objetivamente para dar sentido a la posibilidad del error. ¿Cómo, si no, dar sentido a la idea de estar equivocado acerca de cómo es el mundo? En esta concepción, los contenidos de mis experiencias no son anteriores a la operación de mis capacidades conceptuales, de mi visión del mundo, porque algo cuyas credenciales epistémicas no pueden ser comprobadas no puede servir de fundamento para episodios epistémicos tales como conocer o juzgar.

Desgraciadamente, el realismo científico de Sellars que he comentado brevemente no termina con su propuesta de considerar a las sensaciones como constructos teóricos necesarios para ofrecer una explicación científica del papel de la experiencia. Para Sellars, además de los elementos conceptuales que sirven para situar a la percepción en el espacio de las razones, una comprensión completa de la percepción requería una mención de la sensación, es decir, de un elemento no conceptual. Este elemento parece necesario para dar una explicación científica de nuestra sensibilidad, del impacto sensorial que 
recibimos del mundo. Esto no es problemático, ya que una explicación científica de la sensación tiene como objetivo dar cuenta del vínculo causal entre el mundo y, digamos, nuestro sistema nervioso y por tanto no se la puede acusar de intentar derivar justificación y normatividad de meras causas. Sin embargo, el papel que el factor no conceptual juega para Sellars en la percepción es explicar el elemento conceptual, las afirmaciones que están "contenidas", en paralelo con los juicios, en la experiencia perceptual. Pero no parece que sea necesario apelar a las sensaciones: las afirmaciones que la experiencia perceptual contiene, tales como "parece como si hubiera dos velas rojas enfrente de mí" pueden acreditarse a los objetos cuyo impacto en mi sistema nervioso dispara (causalmente) un episodio conceptual, sin necesidad de postular sensaciones no conceptuales que entren en mi conciencia.

En Ciencia y metafísica, por ejemplo, Sellars hace uso de las sensaciones no para la explicación científica, sino para la explicación trascendental: este uso "está dirigido a mostrar el derecho a concebir las ocurrencias subjetivas como poseedoras de significado objetivo" (Sellars, 1968, p. 445). McDowell rechaza esta concepción de la filosofía trascendental y se acusa a sí mismo de haber seguido a Rorty en el error de concebir los planteamientos trascendentales como planteamientos que miran "desde fuera" (from a sideways-on point) la relación entre las capacidades conceptuales y aquello que conceptualizan (es decir, de considerar que la filosofía trascendental está necesariamente contaminada por los errores del mito de lo dado). ${ }^{17} \mathrm{El}$ papel que Sellars le asigna a las sensaciones en 1968 es el de ser estados de la conciencia, aunque no objetos de la conciencia (evitando así el mito de lo dado, pero no la navaja de Occam). Estos estados de la conciencia le permiten a nuestros estados conceptuales estar dirigidos al mundo, siempre y cuando sean estados y no se conviertan en objetos de la conciencia. Al establecer esta distinción entre estados y objetos de conciencia Sellars abre un espacio para la idea de una receptividad pura y, por tanto, da un gran paso en la dirección del realismo

\footnotetext{
${ }^{17}$ Es cierto también que parte de la responsabilidad está en la confusión terminológica que puede encontrarse en el libro de Strawson Los límites del sentido (1966), donde se contrasta el enfoque empírico con el trascendental, cuando el contraste está entre los aspectos empíricos y los trascendentes del pensamiento kantiano, al que me referí al final de la primera parte de este trabajo.
} 
científico. Nuestro esquema conceptual pasa a ser reemplazable "en principio"; las sensaciones pueden ser vistas como entidades científicas a partir de las cuales puede construirse una nueva comprensión de nuestra interacción con el mundo. Ahora las sensaciones puras, no conceptuales, pueden jugar el papel explicativo que la ciencia les asigna en la comprensión causal de la experiencia y, al mismo tiempo, formar parte de la comprensión filosófica de las condiciones de posibilidad de la experiencia entendida como la relación entre el impacto del mundo y nuestra comprensión de éste. En otras palabras, mientras que las sensaciones puras no tienen ningún lugar en la epistemología en tanto que ésta es una teoría de la justificación del conocimiento, sí que tienen un papel tanto científico como trascendental: para que nuestros pensamientos tengan contenido, estén dirigidos a objetos, el mundo debe poner nuestro aparato conceptual en movimiento "introduciéndose" en nuestra conciencia sin mediación del entendimiento.

El aspecto central de la crítica de McDowell al papel trascendental que Sellars asigna a las sensaciones es que Sellars no parece tener en cuenta que los objetos de experiencia podrían jugarlo. No obstante, lo que motiva el que ignore esta opción es precisamente el realismo científico que persigue. Sellars propone reemplazar los objetos manifiestos que son accesibles a la experiencia (con la mediación de habilidades conceptuales que son parte inseparable de la percepción) por constructos científicos tales como las sensaciones puras. No existe ninguna razón clara por la que tal reemplazo deba tener lugar, aparte de un compromiso previo con la imagen científica.

En "Philosophy and the scientific image of man" (Sellars, 1963b) Sellars mantiene que la tarea de la filosofía es, idealmente, el estudio de la imagen general que emerge de las todas las distintas áreas particulares de conocimiento. No obstante, el filósofo no se encuentra con una concepción multidimensional del ser humano en el mundo, sino con dos "imágenes" del mismo orden de complejidad: las imágenes manifiesta y científica. La imagen manifiesta del ser humano en el mundo es el marco en el que nos encontramos inicialmente: llegamos a ser humanos cuando adquirimos un marco en términos del cual llegamos a ser conscientes de nosotros mismos. Desde el punto de vista de la imagen manifiesta existe una discontinuidad irreductible entre el ser humano y las otras criaturas, un salto holista entre los patrones preconceptuales de comportamiento y el pensamiento conceptual. Sin embargo, la imagen científica ve este paso como continuo y reductible. La imagen manifiesta no es precientífica, acrítica e ingenua. La principal diferencia 
entre las dos es que la imagen científica postula propiedades imperceptibles para explicar el comportamiento de los objetos perceptibles.

Los objetos básicos de la imagen manifiesta son personas. Sellars habla de una 'imagen originaria', de la que la manifiesta es un refinamiento y desarrollo, parra la que todos los objetos personas: el refinamiento consiste en una "despersonalización" de aquellos objetos que no son personas (donde, aunque Sellars no lo dice explícitamente, las personas son aquellas entidades que se ven a sí mismos y a otros como personas, i.e., entidades para las que la imagen manifiesta es manifiesta, sea en su forma originaria o refinada). En tanto en cuanto la imagen manifiesta sea caracterizada por el carácter central de la noción de persona, la cuestión que pende sobre ella es si el proceso de despersonalización debería continuar hasta incluir al propio ser humano. Algunas de las razones para censurar esa extensión son poderosas, pero no pueden sostenerse independientemente de la esperanza de conservar la imagen manifiesta: convertir a los humanos en objetos significa perder la libertad, la voluntad y la moralidad. La invocación de esta idea está en la base de la oposición de Kant a la fuerza arrolladora de la ciencia. Hay otra estrategia, más contemporánea (Wittgenstein, Strawson): aquí las razones no son meramente negativas (si la imagen manifiesta se va, con ella se va la ética), sino motivadas positivamente. Sólo partiendo de la esfera de lo normativo es posible la valoración, y sin valoración todas las imágenes (sean manifiestas o científicas) desaparecen. La reducción de la imagen manifiesta a la científica, o su eliminación, nos deja sin base para defender la validez, la veracidad de la imagen científica. Volveré a este punto.

La imagen manifiesta podría también verse, no como un refinamiento de la imagen originaria, sino como la imagen originaria misma refinada por medio del conocimiento reflexivo de verdades: este conocimiento puede venir de una variedad de fuentes, por ejemplo la ciencia, y su principal efecto sería circunscribir las entidades a las cuales la imagen originaria es aplicable, i.e. circunscribir el reino de las personas. Los cánones de corrección, los elementos evaluativos y normativos, pertenecen a la imagen manifiesta más como un "saber cómo" que como un "saber que". El análisis lógico, la formulación explícita de reglas de comportamiento (incluyendo sistemas éticos), son actividades que pueden ayudarnos a comprender nuestro lugar en el mundo. Análogamente, una forma de evitar el choque entre dos imágenes en conflicto es ver la imagen manifiesta no como una colección (cambiante) de verdades acerca de personas y objetos, sino como una actitud que distingue entre 
personas y objetos, ayudada, eso sí, por formas de conocimiento explícito (con la ciencia probablemente ocupando un lugar privilegiado) para dar contenido a la distinción y para delimitar lo que son personas de lo que no lo son.

Otra forma de expresar esta idea es decir que la imagen manifiesta no es una imagen teórica, mientras que la científica sí lo es. La imagen manifiesta es anterior a la científica en dos sentidos: aparece primero y además nuestra empresa justificadora se apoya en ella. El propio Sellars dice algo parecido: "Así 'la' imagen científica es una construcción a partir de varias imágenes, cada una de las cuales está apoyada en el mundo manifiesto" (ibid., p. 20). Pero dar prioridad metodológica a la imagen manifiesta no implica mantener su prioridad sustancial: Sellars considera, como hemos visto, que ambas imágenes son rivales y que la imagen científica aspira a ofrecer una explicación completa, toda la verdad.

El contraste entre ambas imágenes es explicado por Sellars en términos del contraste entre 'objetos manifiestos' y 'partículas imperceptibles', un contraste que cambia el prisma con respecto a la caracterización de la imagen manifiesta por medio de la noción de persona que he comentado antes. Sellars contempla tres concepciones alternativas de la relación entre ambos marcos: los primeros (objetos manifiestos) son idénticos a sistemas de las segundas (partículas imperceptibles); los primeros existen realmente y las segundas son instrumentos para comprenderlos; y los primeros son meras apariencias mientras que la realidad está constituida por las segundas. Una dificultad que todas estas opciones comparten es que toman a la imagen manifiesta como algo que podemos trascender y evaluar desde fuera (Sellars, 1963b, p. 28). Pero la objeción más obvia es que Sellars ha pasado de definir la imagen manifiesta por la centralidad de la noción de persona (ver Sellars, 1963b, pp. 9-14) a compararla con la imagen científica en términos de observabilidad de objetos: la imagen manifiesta trabaja con objetos de tamaño medio, la científica con imperceptibles. Parece que de esta forma estaría ignorando el aspecto normativo de la imagen manifiesta y comparándola con la científica como la física de sentido común podría compararse con la ciencia moderna. En este sentido, se podría pensar que Sellars no ha terminado de sacudirse el descriptivismo que pervive de la herencia cartesiana, según el diagnóstico con el que he comenzado este artículo.

El problema no está en si los objetos manifiestos o científicos existen, sino en qué deberíamos pensar que hay. Sólo en la última sección de este artículo ("Putting man in the scientific image") se enfrenta Sellars a esta cuestión: lo 
que es irreductible en el marco de personas es el "debe" que está íntimamente ligado con ser miembro de una comunidad de personas ${ }^{18}$ desde la que puede elucidarse lo que es correcto o incorrecto, verdadero o falso. Este factor no tiene como objeto explicar y clasificar, y por ello no entra en competencia con la ciencia. Sin embargo, es de interés que una vez que Sellars considera el aspecto normativo de la imagen científica se ve obligado no sólo a reconocer su irreductibilidad, sino también a afirmar que "el marco conceptual de personas no es algo que necesite reconciliarse con la imagen científica, sino más bien algo que debe unirse a ella" (ibid., p. 40). Relacionar al mundo y nuestro lugar en él, explicado en "términos científicos", con nuestros propósitos e intenciones no es reemplazar una imagen por otra, sino emplazar una imagen (la científica) dentro de otra (la normativa), o al menos rechazar el dualismo entre ambas imágenes y aceptar que cualquier concepción que las tome como opuestas está fundamentalmente equivocada.

\section{3. RAZÓN Y NATURALEZA}

¿Cómo puede articularse la compatibilidad entre, por un lado, la aceptación de la actitud natural como una estructura desde la que dar cuenta del conocimiento y, por otro, el realismo científico? En su influyente obra Mind and World, McDowell ofrece un original diagnóstico de la relación entre la razón y la ciencia y una no menos original propuesta que persigue entender la naturaleza de tal forma que las personas sean parte de ella sin que por ello tengan que ser explicadas nomológicamente. Nuestro autor señala que, al situar su campo de estudio fuera del espacio lógico de las razones, la ciencia "desencanta" (en expresión de Max Weber) a la naturaleza, la vacía de significado. Las conexiones de justificación en la imagen científica de la naturaleza no se encuentran ya en la naturaleza misma dado que ésta se identifica con el 'reino de las leyes'. Algo es parte de la naturaleza (es decir, algo

\footnotetext{
18 "Sin embargo, el carácter esencialmente social del pensamiento conceptual se hace claramente presente cuando reconocemos que no existe pensamiento al margen de los cánones compartidos de corrección y pertinencia que relacionan lo que yo de becho pienso con lo que cualquiera debería pensar. El contraste entre 'yo' y 'cualquiera' es esencial para el pensamiento racional" (ibid., pp. 16-7).
} 
es causalmente eficaz) sólo si es subsumible por leyes. Esta idea es la que lleva a Davidson y a Evans (que representan para McDowell respectivamente el coherentismo y el mito de lo dado) ${ }^{19}$ a rechazar la posibilidad de explicar la racionalidad naturalistamente (ver McDowell, 1994a, capítulo IV).

McDowell contempla tres respuestas a la pregunta sobre el estatuto de la razón. La primera la llama "naturalismo craso" (bald naturalism). La razón debe ser explicada usando los mismos términos que se utilizan para localizar las cosas dentro de la naturaleza: “(...) podemos reconstruir la estructura del espacio de las razones a partir de materiales conceptuales que ya existen en la imagen natural-científica de la naturaleza" (McDowell, 1994a, p.73). El oponente de esta forma de naturalismo mantiene que el contraste entre ambos espacios lógicos es genuino. McDowell distingue dos líneas de oposición. La primera es la suya (y también podría atribuirse a Strawson en la interpretación que de él he ofrecido en la primera parte de este trabajo): los poderes conceptuales operan en la experiencia, siendo esta operación la actualización de nuestra naturaleza humana. Esta propuesta resiste la idea de que la única forma de ser natural es estar situado en el espacio lógico de las leyes y fuera del de las razones. La segunda línea de oposición la representa Davidson: el entendimiento no puede situarse dentro de la naturaleza ya que los conceptos que necesitamos para dar sentido de él están gobernados por el "ideal constitutivo de racionalidad" (ver Davidson, 1970, pp. 221-3). Sin embargo, el monismo anómalo de Davidson mantiene la afirmación ontológica de que los sucesos que caen bajo las redes de lo racional son, en principio, descriptibles usando los conceptos de la ciencia. Es más, tales sucesos están conectados causalmente en tanto que ocupantes del reino de las leyes: "De esta forma una razón puede ser una causa, pero sus conexiones causales no lo son en virtud de sus conexiones racionales" (McDowell, 1994a, p. 75, n. 6). Como es bien sabido, Davidson acompaña su negativa a aceptar que las relaciones causales entre sucesos puedan ocurrir en virtud de sus propiedades mentales la tesis de

\footnotetext{
${ }^{19}$ Hemos visto al principio de este artículo como McDowell relaciona el mito de lo dado atacado por Sellars con la defensa por parte de Evans de la noción de contenido no conceptual. Como veremos a continuación, el rechazo de Davidson de un papel racional para la experiencia lo sitúa en el campo del coherentismo en epistemología.
} 
que la experiencia sólo puede entenderse como una conexión causal entre un sujeto y el mundo: sólo una creencia puede justificar otra creencia. ${ }^{20}$

La propuesta de McDowell, expresada en los términos de la presente discusión, es que "[n]ecesitamos devolver la sensibilidad al significado a las operaciones de nuestras capacidades sintientes naturales al tiempo que insistimos en que tal sensibilidad al significado no puede ser capturada en términos naturalistas si "naturalista" se explica en términos del reino de las leyes" (ibid., p. 77). De esta forma, podemos comprender los ejercicios de nuestras capacidades racionales desde el prisma de su papel en un modo de vida: este es todo el naturalismo que necesitamos ya que podemos, al mismo tiempo, dar cuenta de nuestra naturaleza animal y de las peculiaridades de nuestra condición de criaturas racionales y lingüísticas.

Este naturalismo mínimo y no dependiente de las ciencias naturales para su definición es un naturalismo de 'segunda naturaleza'. McDowell usa una analogía con la ética de Aristóteles para explicar su concepción de la relación entre los dos espacios lógicos, el de las razones y el de las leyes. La concepción de Aristóteles de la naturaleza no la identifica con el reino de las leyes y está exenta de las preocupaciones epistemológicas que la acompañan en la filosofía moderna.

Para fijar la manera en la que esta concepción nos puede servir de modelo, consideremos la noción de segunda naturaleza. (...) La segunda naturaleza no puede comprenderse como si estuviera flotando libremente al margen de las potencialidades que le son propias a un organismo humano normal. Esto le da a la razón humana suficiente asidero en el reino de las leyes como para satisfacer el respeto necesario hacia la ciencia natural moderna. (...) [L]legamos a la idea de tener

\footnotetext{
${ }^{20}$ En Davidson existe una tensión entre, por una parte, sus tesis sobre la interpretación radical y su necesaria presunción de racionalidad y, por otra, sus escritos sobre la relación entre razones y causas. En el presente contexto esa tensión se manifiesta en el contraste entre el carácter ontológico de la identidad entre eventos mentales y físicos, y la negativa a ofrecer un enfoque ontológico de lo mental que alimenta su principio de caridad. Dicha negativa es explorada magistralmente por Bjørn Ramberg en "Post-ontological philosophy of mind: Rorty versus Davidson" (2000). Esta tensión podría ser un síntoma de un descriptivismo residual en Davidson.
} 
abiertos los ojos a las razones adquiriendo una segunda naturaleza. No puedo pensar en una buena expresión sencilla en inglés para esto, pero es la idea que aparece en la filosofía alemana como Bildung (ibid., p. 84).

La noción de segunda naturaleza nos permite mantener la naturaleza parcialmente "encantada" sin por ello regresar a la superstición precientífica. Según McDowell, Kant se acerca mucho a esta conclusión al no aceptar ninguna de las tres opciones rechazadas por McDowell (mito de lo dado, coherentismo, naturalismo craso). Sin embargo, al no contemplar la posibilidad de un naturalismo de segunda naturaleza, no le queda otra opción que situar la conexión entre intuiciones y conceptos (e igualmente, podríamos añadir, entre lo causal y lo racional) fuera de la naturaleza, en un contexto que distingue entre lo fenoménico y lo nouménico. McDowell también llama a este naturalismo de segunda naturaleza 'platonismo naturalizado'. Es 'platonismo' porque le confiere una cierta autonomía a la esfera de la razón, y está 'naturalizado' dado que esa esfera no está aislada de lo "meramente" humano, como en el 'platonismo galopante' (rampant platonism).

\section{CONCLUSIÓN}

Lo que queda de la imagen manifiesta después de la crítica de Sellars es lo que he llamado, siguiendo a Strawson, la actitud natural, es decir, el marco normativo de personas y valores (morales y estéticos, pero también valores de verdad) desde el que pueden evaluarse las teorías, las concepciones y las imágenes. He mantenido que el vocabulario y la investigación científica no pueden aislarse del resto de conocimiento y lenguaje humanos. Así, el realismo científico, tal y como es entendido por Sellars, no es análogo al realismo con respecto a la imagen manifiesta. He mantenido, con Strawson, que la imagen manifiesta no es un conjunto de creencias que tienen prioridad sobre otras creencias, las de nuestras teorías científicas actuales. Nuestra comprensión del mundo en términos de personas y objetos no debe oponerse a nuestra comprensión en términos de las entidades postuladas por la ciencia. Es más bien una condición de posibilidad de nuestro conocimiento del mundo, incluyendo el conocimiento científico, una indicación de cuáles son los observables fundamentales y cómo están estructurados en nuestra experiencia.

Strawson expresa este punto con particular claridad. En su crítica a la teoría de la percepción de Ayer (ver Ayer, 1973, pp. 68-111) argumenta que los juicios perceptuales llevan con ellos una cierta visión del mundo según la cual 
éste contiene objetos, situados en un espacio común, con una variedad de propiedades. Nuestros juicios implican la aplicación de conceptos a esos objetos. Strawson señala que esto no significa que tal visión del mundo deba ser verdadera, sino más bien que "nuestra experiencia sensible no podía haber tenido el carácter que tiene a no ser que_al menos antes de que la reflexión filosófica entre en escena-tomemos incondicionalmente como verdadera esa visión general del mundo" (Strawson, 1979, p. 96). Una consecuencia importante de esto es que la visión realista del mundo que subyace a nuestros juicios perceptuales no puede tener el estatuto de una teoría con respecto a la experiencia sensible.

Strawson insiste en que el punto de vista de sentido común y el científico no deben considerarse incompatibles, y su rechazo de que el primero sea una teoría evita la dificultad de tener que optar por su eliminación. Porque incluso si el realista científico quiere proclamar la superioridad de la ciencia sobre el marco de sentido común sólo puede estar expresando una preferencia. Y si mantiene que la ciencia mina el sentido común, sólo puede hacerlo ignorando el hecho de que no sólo la ciencia es una criatura del sentido común, sino que permanece dentro de sus dominios. El realista científico debe admitir que la adscripción de cualidades sensibles a objetos y los cánones intersubjetivos de corrección de tales adscripciones están fuertemente apoyados en nuestra visión general del mundo. Y esta visión, que nuestro realista científico puede insistir en llamar una ilusión persistente, es la condición de posibilidad de nuestra participación en la actividad científica misma.

En este trabajo he defendido una concepción del papel de la ciencia que no se compromete con el monismo fisicista ni, más generalmente, con el cientifismo. Para ello me he unido a las filas de Strawson y Kant, como ejemplos de filósofos que dan prioridad a la noción de persona con respecto al par mente / cuerpo. Tras una discusión de la crítica de Sellars al mito de lo dado he puesto objeciones a su realismo científico y argumentado en favor de la compatibilidad de nuestro compromiso ineludible con el marco normativo de la actitud natural y nuestra admiración por los resultados de la investigación científica. Esta compatibilidad sólo tiene sentido a partir de una posición que subraya los valores subyacentes (epistémicos, pero también prácticos) que la ciencia necesita para poder reclamar ser una fuente de conocimiento. El naturalismo (entendido como la reducción de lo normativo a lo descriptivo) 
presupone una distinción radical entre hechos y valores y tal distinción es ella misma evaluativa y no factual.

Manuel de Pinedo

Universidad de Granada

pinedo@ugr.es

\section{BIBLIOGRAFÍA}

Allison, H. (1983), Kant's Transcendental Idealism, New Have, Yale University Press

AYer, A.J. (1962), How to Do Things with Words, Oxford, Clarendon.

AYer, A.J. (1973), The Central Questions of Philosophy, London, Weidenfeld and Nicholson.

Ayer, A.J. (1982), Philosopby in the Twentieth Century, London, Unwin.

BRANDOM, R. (1997), "Study guide to Wilfrid Sellars's Empiricism and the Philosophy of Mind", Cambridge, Mass., Harvard University Press, pp. 119-81.

BRANDOM, R. (2000), "Semantic inferentialism and logical expressivism", en Brandom, Articulating Reasons, Cambridge, Mass., Harvard University Press.

CHILD, W. (1994), Causality, Interpretation and the Mind, Oxford, Clarendon Press.

Chomsky, N. (1979), Language and Responsibility, New York, Pantheon Books (basado en conversaciones con Mitsou Ronat y traducido del francés por J.Viertel).

Chomsky, N. (1995), "Language and nature", Mind 104, 1-61.

Chrisman, M. (2007), "From epistemic contextualism to epistemic expressivism”, Philosophical Studies 133, 225-54.

CoHEN, J. (1981), "Can human irrationality be experimentally demonstrated", The Behavioral and Brain Sciences 4, pp. 317-70.

Cohen, J. (1993), "Rationality", en J. Dancy y E. Sosa (eds.), A Companion to Epistemology, Oxford, Blackwell, 1993, pp. 415-20.

Davidson, D. (1970), "Mental events", en Davidson, Essays on Actions and Events, Oxford, Clarendon Press, 1980, pp. 207-25. 
DAvidson, D. (1974), "On the very idea of a conceptual scheme", en Davidson, Inquires into Truth and Interpretation, Oxford, Clarendon Press, 1984, pp. 183-98.

Davidson, D. (1977), "The method of truth in metaphysics", en Davidson, Inquires into Truth and Interpretation, Oxford, Clarendon Press, 1984, pp. 199-214.

Davidson, D. (1982), "Rational animals", dialectica 36, 317-27.

DAvidson, D. (1990), "The structure and content of truth", Journal of Philosophy 87, 279-328.

DennetT, D.C. (1971), "Intentional systems", en Dennett, Brainstorms, Brighton, The Harvester Press, 1978, pp. 3-22.

DENNETT, D.C. (1978), "Towards a cognitive theory of consciousness", en Dennett, Brainstorms, Brighton, The Harvester Press, 1978, pp. 149-73.

DennetT, D.C. (1979), "True believers", en Dennett, The Intentional Stance, Cambridge, Mass., The MIT Press, 1987, pp. 13-35.

DennetT, D.C. (1981), "Making sense of ourselves", en Dennett, The Intentional Stance, Cambridge, Mass., The MIT Press, 1987, pp. 83-101.

DennetT, D.C. (1987), "Evolution, error and intentionality", en Dennett, The Intentional Stance, Cambridge, Mass., The MIT Press, 1987, pp. 287-321

DennetT, D.C. (1995), Darwin's Dangerous Idea, New York, Simon and Schuster.

Evans, G. (1980), "Things without the mind. A commentary upon chapter two of Strawson's Individuals", en Z. van Straaten (ed.), Philosophical Subjects. Essays presented to P. F.Strawson, Oxford, Clarendon Press, 1980, pp. 76-116.

Evans, G. (1981), “Understanding demonstratives”, en S.H. Holtzman y C.M. Leich (ed.), Wittgenstein: To Follow a Rule, London, Routledge, 1981, pp. 118-37.

Evans, G. (1982), The Varieties of Reference, Oxford, Clarendon Press; edited by John McDowell.

Finkelstein, D. (2008), Expression and the Inner, Cambridge, Mass., Harvard University Press.

FrÁpolli, M. J., (2012), The Nature of Truth. An Updated Approach to the Meaning of Truth Ascriptions, Amsterdam, Springer.

FrÁpolli, M. J. \& VillanueVa, N. (2012), "Minimal expressivism", dialectica 66, 471-87. 
Gibbard, A. (1990), Wise Choices, Apt Feelings, Cambridge, Mass., Harvard University Press.

Gould, S. J. (1977), "Of bamboos, cicadas and the economy of Adam Smith", en Ever Since Darwin, Norton 1977.

Gould, S. J. Y R. LEWONTIN (1979), "The spandrels of San Marco and the Panglossian paradigm - a critique of the adaptationist programme", Proceedings of the Royal Society of London, B 205, 581-98.

HACKER, P. M.S. (1986), Insight and Illusion (Revised edition), Oxford, Clarendon Press.

Hegel, G.W.F. (1807), Fenomenología del Espititu, México, Fondo de Cultura Económica, 1966; traducción de Phänemonologie des Geistes (Hamburgo, Félix Meier) por Wenceslao Roces.

Hume, D. (1739-40), A Treatise of Human Nature, Oxford, Clarendon Press, 1978 ( $2^{a}$ edición), editado por L.A. Selby-Bigge, texto revisado por P. H. Nidditch [traducción española de Félix Duque, Madrid, Editora Nacional, 1981].

JAMES, W. (1912), Essays in Radical Empiricism, New York, Longmans Green.

JOHnson-Laird, P. Y P. WASON (eds.) (1977), Thinking, Cambridge, Cambridge University Press.

KANT, I. (1781/7), Crítica de la razón pura; traducción de Kritike der reinen Vernunft (Riga, Hartknoch) por Pedro Ribas.

LANGTON, R., Kantian Humility, Oxford, Oxford University Press.

MaYnard SMith, J. (1958), The Theory of Evolution, Cambridge, Cambridge University Press.

MCDowell, J. (1977), "On the sense and reference of a proper name", en J. McDowell, Meaning, Knowledge, and Reality, Cambridge, Mass., Harvard University Press, 1998, pp. 171-98.

MCDoweLL, J. (1985), "Functionalism and anomalous monism", en E. LePore y B. McLaughlin (eds.), Actions and Events: Perspectives on the Philosophy of Donald Davidson, Oxford, Blackwell 1985, pp. 387-98.

McDowell, J. (1994), Mind and World, Cambridge, Mass., Harvard University Press.

MCDowell, J. (1994b), "The content of perceptual experience", The Philosophical Quarterly 44, 190-205.

McDowell, J. (1998), "Having the world in view: Sellars, Kant, and intentionality" (versión revisada de las Woodbridge Lectures; Columbia University, 15, 16 y 17 de abril, 1997), Journal of Philosophy 95, 431-91. 
McGinn, C. (1981), The Problem of Consciousness, Oxford, Blackwell

ORTEGA Y GASSET, J. (1940), "Ideas y creencias”, en Ortega y Gasset, Ideas y creencias, Madrid, Espasa Calpe, 1959 (6 $6^{a}$ edición).

PINEDO, M. (2002), "De la imagen manifiesta a la actitud natural. El lugar de la ciencia en nuestra comprensión del mundo", Daimón 25, 145-62.

Pinedo, M. (2006), "Anomalous monism: Oscillating between dogmas", Synthese 148: 79-97.

Pinedo, M. \& Noble, J. (2008), "Beyond persons: extending the personal / subpersonal distinction to non-rational animals and artificial agents", Biology and Philosophy, 23 (1), 87-100.

Price, H. (2011), Naturalism without Mirrors, Oxford, Oxford University Press.

RAmberG, B. (2000), "Post-ontological philosophy of mind: Rorty versus Davidson" en Brandom (ed.), Rorty and his Critics, Oxford, Blackwell, pp. 351-70.

Ryle, G. (1949), The Concept of Mind, Nueva York, Penguin, 1963.

RorTy, R. (1980), Philosophy and the Mirror of Nature, Oxford, Blackwell.

SELLARS, W. $\left(1963^{\mathrm{a}}\right)$, "Empiricism and the philosophy of mind", en Sellars, Science, Perception and Reality, London, Routledge and Kegan Paul, 1963, pp. 127-96.

SELLARS, W. (1963b), "Philosophy and the scientific image of man", en Sellars, Science, Perception and Reality, London, Routledge and Kegan Paul, 1963, pp. 1-40.

Sellars, W. (1968), Science and Metaphysics. Variations on Kantian Themes, London, Routledge.

STICH, S. (1981), "Dennett on intentional systems", Philosophical Topics 12, pp. 38-62.

STICH, S. (1990), The Fragmentation of Reason, Cambridge, Mass., The MIT Press.

Strawson, P. F (1959), Individuals (An Essay in Descriptive Metaphysics), London, Methuen.

Strawson, P. F. (1966), The Bounds of Sense (An Essay on Kant's Critique of Pure Reason), London, Methuen.

Strawson, P. F. (1979), "Perception and its objects", en J. Dancy (ed.), Perceptual Knowledge, Oxford, Oxford University Press, 1988, pp. 92-112.

Strawson, P.F. (1985), Skepticism and Naturalism: Some Varieties (The Woodbridge Lectures 1983), New York, Columbia University Press. 
TVERSKY, A. y D. KAHNEMAN, (1983), "Extensional versus intuitive reasoning: the conjunction fallacy in probability judgment", Psychological Review 90, pp. 293-315.

VAN FraAsEN, B. C. (1989), Laws and Symmetry, Oxford, Clarendon Press.

Wittgenstein, L. (1921), Tractatus Logico-Philosophicus, Madrid, Revista de Occidente, 1957; traducción de Logisch-philosophische Abhandlung por Enrique Tierno Galván.

Wittgenstein, L. (1953), Philosophical Investigations, Oxford, Blackwell; trad. de Philosophische Untersuchungen por G.E.M. Anscombe, ed. por G.E.M. Anscombe and R. Rhees.

Wittgenstein, L. (1969), Sobre la certeza, Barcelona, Gedisa, 1988; traducción de Über Gewissheit (Oxford, Blackwell) por Joseph Lluís Prades y Vicent Raga. 